\title{
DISCUTINDO GÊNERO E COZINHA: A DIVISÃO SEXUAL DO TRABALHO EM UMA COZINHA PROFISSIONAL NA CIDADE DE SALVADOR/BA
}

\author{
DISCUSSING GENDER AND KITCHEN: THE SEXUAL DIVISION OF \\ LABOR IN A PROFESSIONAL KITCHEN IN THE CITY OF SALVADOR / BA
}

\section{Resumo}

Este artigo discute a divisão sexual do trabalho em uma cozinha profissional, bem como as posições ocupadas por homens e mulheres no espaço. A pesquisa foi realizada em um Restaurante Institucional na cidade de Salvador/BA, através de observações na cozinha local e entrevistas semiestruturadas realizadas com (sete) pessoas que trabalhavam diretamente com o preparo de alimentos. A análise dos dados foi realizada com base nos Núcleos de Significação, instrumento que busca apreender os sentidos e significados das falas por meio do contexto sócio histórico, base da Psicologia Sócio Histórica. Utilizou-se também o gênero como categoria analítica, assim como nos estudos feministas. Foi observado que a força de trabalho masculina assume papéis proeminentes no trabalho em cozinha, como lidar com a carne e manejar o fogão, enquanto os femininos ficam a feminina fica à margem do processo de produção, a exemplo do manuseio de vegetais e tarefas que são mais repetitivas.

Palavras-chave: Divisão Sexual do Trabalho. Gênero. Cozinha Profissional. Trabalho Culinário.

\begin{abstract}
This article discusses the sexual division of labor in a professional kitchen, as well as the positions occupied by men and women in space. It was developed in an Institutional Restaurant in the city of Salvador/BA, through observations in the local kitchen and semi-structured interviews with (seven) people who worked directly with the food production. The analysis of the data was carried out through the Nuclei of Meaning, an instrument that seeks to apprehend the senses and meanings of the speeches through the socio-historical context, the basis of the Historical Social Psychology. Gender was also used as an analytical category, as well as in feminist studies. It has been observed that the male workforce assumes prominent roles in kitchen work, such as handling meat and stove management, while the female labor force is at the margins of the production process, such as vegetable handling and the tasks that are more repetitive.
\end{abstract}

Keywords: Sexual Division of Work. Gender. Professional Kitchen. Culinary Work.

Gabriela Brito de Lima Silva

Universidade Federal da Bahia. E-mail: gabii.bls2o@gmail.com

Patrícia S. Rezende

Faculdade de Ceilândia / Universidade de Brasília. E-mail: psrezende@gmail.com

Virgínia C. Machado

Universidade Federal da Bahia. E-mail: virginia.campos@ufba.br 


\section{Introdução}

Este texto propõe discutir a divisão sexual do trabalho na cozinha profissional a partir de uma pesquisa intitulada "Gênero e Cozinha Profissional: A organização de uma cozinha profissional na cidade de Salvador/BA". Este estudo objetivou analisar relações de gênero em uma cozinha profissional, buscando compreender como a dinâmica de trabalho do local estudado estava organizada sob critérios de gênero. A pesquisa foi desenvolvida em um Restaurante Institucional (RI) na cidade de Salvador/BA, através de observações e entrevistas com pessoas que trabalhavam diretamente com a produção da alimentação.

A divisão sexual do trabalho é uma das estruturas baseadas nos preceitos da concepção de gênero. Segundo Kergoat \& Hirata (2007) ela é uma forma de divisão social do trabalho decorrente das relações de sexo, se adaptando historicamente e a cada sociedade, tendo como característica a orientação prioritária dos homens à esfera social produtiva e das mulheres à reprodutiva. Como consequência, os homens são associados às funções com maior valor social agregado (políticos, religiosos, militares, etc.).

Como ressaltado por Scott (1990), o gênero indica o modo inteiramente social dos papéis atribuídos às categorias mulher e homem e coloca em ênfase todos os sistemas de relação em que se pode incluir o sexo. Desta maneira, trata-se de uma construção social e cultural em torno dos sexos, marcada por relações de poder, produzidas nas mais diferentes dimensões sociais, dentre elas o mundo do trabalho.

Hirata \& Kergoat (2007) destacam que a divisão sexual do trabalho tem dois princípios organizadores: o de separação (há atividades de homens e atividades de mulheres) e hierarquização (um trabalho de homem vale mais que um trabalho de mulher). Em relação a cozinha profissional, sinalizamos um estudo realizado por Castro e Maffia (2012) com trabalhadoras de uma cozinha profissional, no qual as autoras perceberam que o gênero exercia influência em alguns aspectos relacionados a organização do trabalho. As autoras observaram que existiam diferenças nas atividades exercidas por homens e mulheres, como por exemplo, o manuseio de carnes e a remoção do lixo - sendo masculinas - e preparo de saladas e doces - sendo femininas. Além disto, o estudo observou que os homens ainda possuíam vantagens, como a ascensão profissional e a ocupação de cargos de liderança, como os de chef e cozinheiro.

Enquanto as mulheres estão relacionadas as trabalho culinário cotidiano, o trabalho masculino se direciona para as atividades vistas como especializadas e privilegiadas no mundo do trabalho em cozinha. A profissionalização da cozinha, através da passagem do trabalho relativo ao preparo da comida do espaço privado para o público, acentuou as relações de gênero, delimitando "quem cozinha", "para quem cozinha" e "como cozinha”. Anterior a esse momento, era comum que as mulheres estivessem relacionadas ao preparo da alimentação no âmbito doméstico (e ainda se mantém), estando nas mãos delas o dever de alimentar e nutrir a família. 
Porém, com a incorporação da atividade de cozinhar no mercado de trabalho e em espaços de prestígio, a cozinha passou a representar a imagem masculina (Collaço, 2008; Barbosa, 2012). É importante pontuarmos que tal transformação não deve ser compreendida como algo natural da relação entre mulheres e homens com o mundo o trabalho, mas trata-se de relações de poder engendradas socialmente que são reproduzidas, também, na esfera do labor culinário.

Ao se tratar da inserção das mulheres nas cozinhas profissionais, diversos discursos são criados para limitar sua participação nesse campo. Uma das explicações para essas posições, e em consequência para as opressões femininas, é que o trabalho na cozinha profissional é árduo e difícil, sendo inapropriado para mulheres (Dória, 2014). No entanto, destaca-se que o desenvolvimento tecnológico pode ser utilizado para substituir o emprego da força física em determinadas atividades, anulando a justificativa referente à força masculina, que é utilizada como álibi para demarcar posições.

As mulheres quando encarregadas de uma cozinha profissional, não têm o mesmo prestígio que os homens, suas funções transitam nas cozinhas consideradas de menor valor (como as cozinhas coletivas, comunitárias, escolares e Pratos Feitosi). Uma possível explicação para a desvalorização do trabalho feminino nesse contexto é sua associação ao trabalho doméstico, tido como não produtivo, e aos estereótipos criados em torno da figura feminina. Mesmo havendo algumas chefs e cozinheiras, ainda circula a ideia de que a cozinha profissional (local de racionalidade) não pode ser contaminada pelo universo feminino, que comumente está associado à simplicidade e ao emocional (Collaço, 2008).

Neste texto focalizaremos na discussão sobre a divisão sexual do trabalho, destacando de que forma o gênero atua como um dos determinantes da organização do labor na cozinha e como os discursos trazidos à tona são marcados por elementos que revelam e conservam relações de poder. Para tanto, buscamos apreender os sentidos e significados atribuídos ao trabalho de homens e mulheres na cozinha, compreendendo que o trabalho não está desvinculado da historicidade dos processos sociais e dos sujeitos, assim como a construção sociocultural do gênero e suas representações. Ou seja, a condição de trabalhadores de cozinha profissional se constitui também na e pela condição de mulher e homem na sociedade.

Para discutir como as questões de gênero estão expressas na constituição de uma cozinha profissional, nos baseamos nos pressupostos da Psicologia Sócio-Histórica (PSH) e utilizamos o gênero como categoria analítica, assim como nos estudos feministas. Em seguida, abordaremos os pressupostos teóricos e metodológicos da pesquisa e seus resultados.

1 Restaurantes populares que servem comidas do cotidiano. Tais estabelecimentos frequentemente comercializam as refeições em porções únicas, para uma ou duas pessoas, tendo sua quantidade determinada por um prato. 


\section{Metodologia}

\section{Referencial teórico-metodológico}

A pesquisa foi desenvolvida nos moldes de um estudo de caso, realizando-se em uma cozinha industrial de um Restaurante Institucional de uma universidade na cidade de Salvador, no Estado da Bahia ${ }^{2}$. Para o desenvolvimento do estudo utilizamos a PSH e seus pressupostos como referencial teórico-metodológico, considerando-a como fundamental na compreensão dos processos e da subjetividade.

A PSH assume o materialismo histórico dialético como filosofia, teoria e método e este concebe a história como um processo contraditório, sendo produto da ação do ser humano em sociedade para a construção de sua própria experiência. Tal concepção representa o que seria a realidade material vivida e construída pelo ser humano. As referências básicas de análise da PSH são as experiências humanas, bem como das ideias produzidas pelos seres humanos como expressão mediada dessas experiências, ou seja, produzir meios materiais para suprir suas necessidades implica necessariamente na produção de ideias e representações sobre elas, estas acabam por refletir sua vida real: ações e relações (Gonçalves, 2002).

Na produção da sua vida material por meio do trabalho, o ser humano é visto como um ser ativo, social e histórico, pois ao transformar a natureza ele consequentemente transforma a si próprio. Vale ressaltarmos que é por meio da atividade significada no mundo que o ser humano não só vai transformar a realidade objetiva em realidade humana, mas também criar suas próprias condições de existência e transformar-se (Gonçalves, 2002; Aguiar, 2000).

Trazemos a PSH como possibilidade de analisar como as experiências das pessoas entrevistadas, a relação com o contexto social na qual estão inseridas e a historicidade dos processos sociais constituem uma totalidade. Desta maneira, compreender como o gênero se tornou elemento fundante da divisão sexual do trabalho e como esta divisão se expressa no labor em uma cozinha profissional, é revelar processos de naturalização, desigualdades e relações de poder.

\section{Produção dos dados}

Para a produção dos dados aplicamos duas diferentes técnicas com o intuito de compreender quais aspectos constituem o trabalho na cozinha profissional, desta forma, utilizamos tanto observações quanto entrevistas semiestruturadas.

A etapa de observações foi desenvolvida na cozinha do RI entre os meses de fevereiro e março de 2016, no período da manhã. Os registros foram feitos em diário de campo, no qual foram incluídas as descrições do local, das trabalhadoras e trabalhadores e das atividades, assim como das conversas informais entre essas

2 O projeto de pesquisa foi submetido ao Comitê de Ética da Escola de Nutrição da Universidade Federal da Bahia tendo como número de parecer 1.406.410. 
pessoas e a pesquisadora. O material gerado foi utilizado como complemento às entrevistas, que foram utilizadas como principal instrumento de produção de dados do estudo. Consideramos necessário compreender como funciona a organização e os níveis hierárquicos da cozinha estudada e quais são os profissionais que atuam no local, para então analisarmos com um nível de profundidade a realidade vivenciada na cozinha.

As entrevistas foram realizadas no mês de março de 2016, conforme disponibilidade dos participantes. Todas assinaram Termo de Consentimento Livre e Esclarecido e permitiram a gravação de suas falas. O critério para seleção das pessoas entrevistadas foi trabalhar diretamente com a produção de alimentos na cozinha do restaurante e seu interesse de participação na pesquisa. Assim, entrevistamos: um cozinheiro, um auxiliar de cozinha, um magarefe 3 , três copeiras e uma auxiliar de cozinha, totalizando sete (7) pessoas. Os nomes foram omitidos para preservação do anonimato, sendo adotados nomes fictícios.

As entrevistas foram transcritas e, posteriormente, analisadas por meio dos Núcleos de Significação, como veremos a seguir.

\section{Análise dos Dados}

Núcleos de Significação é um instrumento de análise que se baseia na Psicologia Sócio-Histórica (PSH) e tem como objetivo nortear o pesquisador no processo de apreensão dos sentidos e significados das falas dos sujeitos articulando com o contexto sócio-histórico na qual estas são produzidas.

Nesse sentido, Aguiar \& Ozella (2013) afirmam que:

Os significados são, portanto, produções históricas e sociais. São eles que permitem a comunicação, a socialização de nossas experiências. Muito embora sejam mais estáveis “dicionarizados", eles também se transformam no momento histórico (Aguiar \& Ozella, 2013, p. 304).

Para os autores, os significados referem-se a conteúdos instituídos socialmente e fixos, que são compartilhados e apropriados pelos sujeitos, configurados a partir de suas próprias subjetividades e quando apreendidos, constituirão os sentidos. Ou seja, os significados são compartilhados socialmente, porém os sentidos se constituem no encontro do sujeito singular com a experiência social concreta.

Portanto, o uso da Psicologia Sócio-Histórica apresenta-se como uma forma de contribuir para a compreensão de como as pessoas que trabalham na cozinha estudada concebem o trabalho; suas experiências se constituem e significam suas práticas em meio a realidade social. Desta maneira, podemos perceber por meio das intepretações das falas de que forma as relações de gênero se inserem no contexto de trabalho de uma cozinha profissional, refletindo a divisão sexual do trabalho.

3 Espécie de açougueiro da cozinha, responsável pelos cortes, porcionamento e pré-preparo das carnes. 
Para a construção dos Núcleos de Significação, é necessário, após a transcrição das entrevistas, realizar várias leituras flutuantes a fim de apropriar-se do material. Em seguida, destacam-se os elementos que se repetem, se complementam ou se contradizem, no qual chamamos de pré-indicadores. Em um segundo movimento de leitura e análise, aglutina-se os pré-indicadores, observando sua complementaridade ou contradição, avaliando frequentemente quais deles condizem com os objetivos da pesquisa. Ao fim, mais um movimento de aglutinação é realizado com o intuito de construir os Núcleos de Significação. Nesse momento busca-se articular as falas à teoria e analisá-las por meio da perspectiva sócio-histórica, tal qual nos sugerem Aguiar \& Ozella (2013).

\section{Resultados e discussão}

Para discutirmos a divisão sexual do trabalho na cozinha profissional, começaremos por apresentar brevemente como se organiza, de modo geral, a cozinha do local estudado, quais são os cargos e quais são setores relacionados ao trabalho. Em seguida, apresentaremos o Núcleo de Significação denominado "lugar de mulher x lugar de homem" que irá discutir mais profundamente a divisão das atividades laborais e o espaço ocupado por mulheres e homens na cozinha do RI.

Algumas notas sobre a organização geral da cozinha

No processo de produção da refeição servida no restaurante participam diversas categorias profissionais: chef de cozinha, cozinheiros, ajudantes de cozinha e copeiras. Todas realizam algum serviço vinculado diretamente à produção da comida em setores específicos. No entanto, ainda que todas participem do processo, há uma hierarquia entre as categorias profissionais citadas, o que ocasiona mais reconhecimento para algumas do que para outras.

O restaurante é gerido por uma empresa terceirizada, porém, é coordenado por uma instituição pública. As pessoas que trabalham diretamente com o preparo das refeições possuem atribuições associadas à higienização dos alimentos, cortes, condimentação, cocção e o serviço da alimentação. Na figura 1 observamos a organização hierárquica da cozinha do restaurante: 
Figura 1. Organização hierárquica da cozinha do RI.

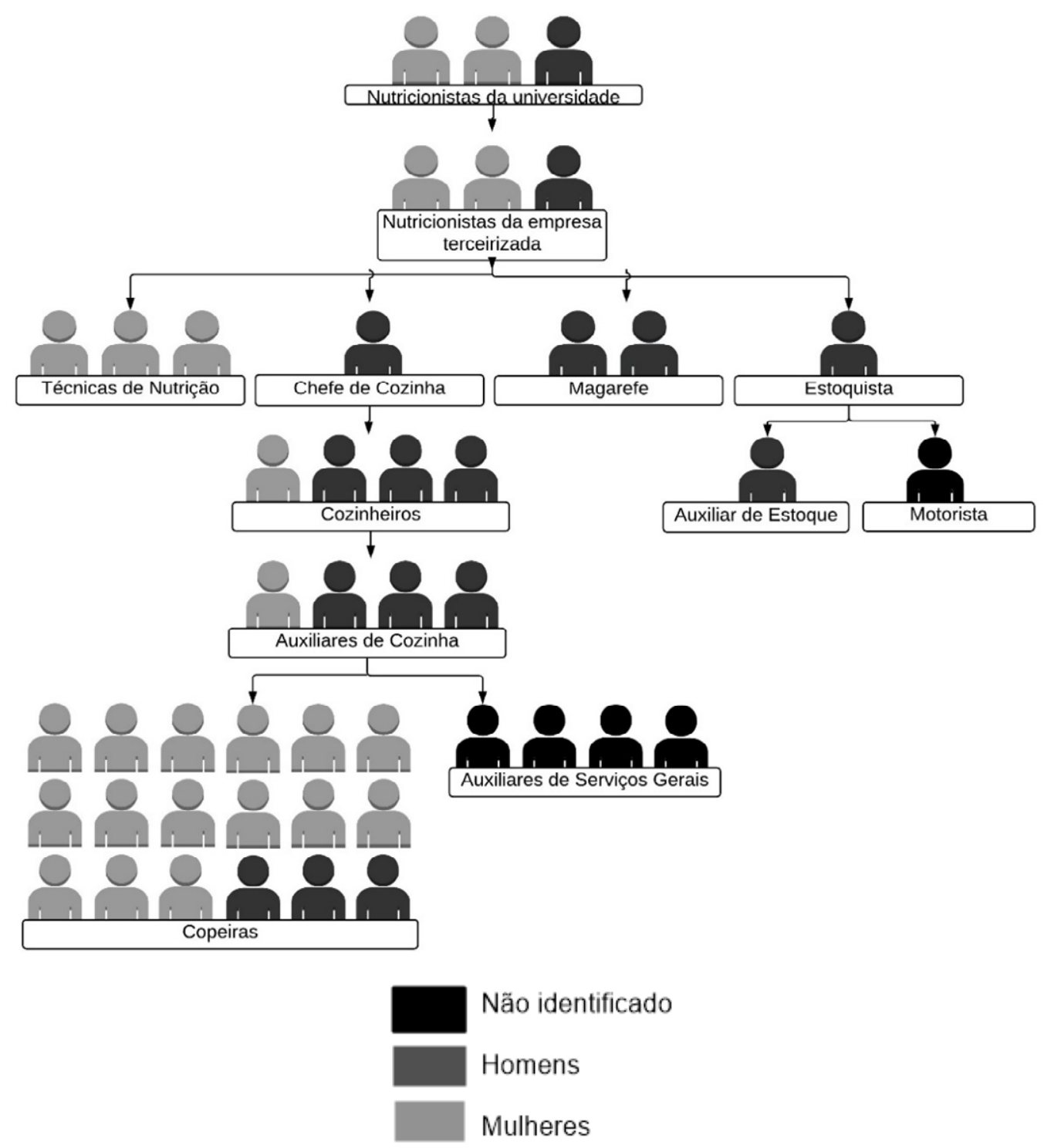

Fonte: Autoras (2018).

Observamos que na hierarquia, as nutricionistas estão nos postos mais altos, tanto da empresa terceirizada quanto da instituição. Dos seis profissionais, quatro são mulheres e dois são homens. Uma possível explicação para a participação das mulheres neste cargo é a sua estreita relação com o curso de nutrição. Passos (1997) afirma que a preponderância das mulheres nos cursos de nutrição e o afastamento masculino da carreira ocorrem pelo fato da área estar vinculada à alimentação e a relação com o cuidado, o que sugere, enquanto identificação, a tarefas femininas.

Desta forma, notamos que as mulheres que estão em níveis hierárquicos mais altos são aquelas que exercem a profissão de nutricionista, reconhecida como profissão essencialmente feminina. Observamos nas literaturas apresentadas (Costa, 2014; Saffiotti, 2010; Hirata \& Kergoat, 2007), que cargos de liderança e destaque muitas vezes são ocupados por homens, o que nos leva a acreditar que, caso não se 
tratasse da profissão de nutricionista, possivelmente haveria dificuldade de ascensão destas mulheres. O mesmo vale para as técnicas em nutrição, que são responsáveis por supervisionar as práticas de manipulação de alimentos dos trabalhadores.

O chef de cozinha, o magarefe e o estoquista são todos homens e com níveis hierárquicos equilibrados na empresa X. O chef é responsável pela supervisão dos demais trabalhadores que atuam na manipulação dos alimentos, além de trabalhar diretamente com o processo de produção. O magarefe é responsável pelo pré-preparo ${ }^{4}$ das carnes. O estoquista é responsável por receber os insumos e materiais solicitados pela empresa terceirizada, além de gerir o armazém, possuindo um auxiliar para suas atividades.

Os cozinheiros, em sua maioria homens, atuam na produção das refeições, também realizando o pré-preparo e cocção dos alimentos, sendo a única cozinheira responsável apenas pelo café da manhã. Os auxiliares de cozinha, também em sua maioria homens, realizam atividades similares à dos cozinheiros, com exceção da cocção das carnes. A única auxiliar de cozinha realiza a preparação da opção ovolácteavegetariana 5 .

As copeiras, em sua maioria mulheres, estão em nível hierárquico mais baixo que os demais trabalhadores. Elas são responsáveis por diversas atividades na cozinha. Atuam no setor de preparo das saladas, higienizam frutas para as sobremesas, servem os comensais, organizam as rampas (locais onde a alimentação é servida) ou até auxiliam os demais profissionais quando necessário. Destacamos que alguns trabalhos das copeiras são realizados de acordo com as demandas de serviço. Os três copeiros são responsáveis apenas pela produção dos sucos que são servidos no restaurante e pela reposição da alimentação nas rampas ${ }^{6}$.

Por fim, para melhor compreensão do estudo, apresentaremos os setores onde as trabalhadoras e os trabalhadores exercem as funções apresentadas no quadro 1. Todas as nomenclaturas estão sendo utilizadas mediante organização original do local e de acordo com o modo no qual as pessoas entrevistadas os identificam.

4 Etapa pela qual os alimentos passam antes de serem finalizados e consumidos, inclui-se a limpeza, higienização, separação de ingredientes, cortes, condimentos etc.

5 Espécie de dieta vegetariana no qual pode-se consumir alguns alimentos de origem animal como ovos, queijos, leites e derivados. No RI oferta-se como opção à substituição da carne/proteína animal na refeição.

6 Nome utilizado pelos entrevistados, para denominar os balcões térmicos onde as preparações são acondicionadas para o serviço. 
Quadro 1. Organização dos setores da cozinha.

\begin{tabular}{|c|c|c|}
\hline Setor & Descrição & Cargos \\
\hline Cozinha quente & $\begin{array}{l}\text { Local de pré-preparo e cocção } \\
\text { do prato principal }\end{array}$ & $\begin{array}{l}\text { Chefe de cozinha, cozinheiro } \\
\text { e auxiliares de cozinha }\end{array}$ \\
\hline Cozinha fria & $\begin{array}{l}\text { Local de preparo da opção } \\
\text { ovolácteavegetariana. }\end{array}$ & Auxiliar de cozinha \\
\hline Sala de saladas & Local de preparo de saladas. & Copeiras \\
\hline Sala de sucos & Local de preparo dos sucos. & Copeiros \\
\hline Açougue & $\begin{array}{l}\text { Local de pré-preparo das } \\
\text { carnes. }\end{array}$ & Magarefes \\
\hline Armazém & $\begin{array}{l}\text { Local de acondicionamento de } \\
\text { insumos e materiais. }\end{array}$ & Estoquista e auxiliar \\
\hline Sala de recebimento & $\begin{array}{l}\text { Local de recepção de insumos e } \\
\text { materiais. }\end{array}$ & Estoquista e auxiliar \\
\hline Rampa & Local de serviço da alimentação. & Copeiras e Copeiros \\
\hline
\end{tabular}

Fonte: Autoras (2018)

Apresentados os cargos, funções e setores, seguiremos com a discussão do Núcleo de Significação.

Núcleo de Significação: "Lugar de mulher e lugar de homem"

Neste tópico apresentaremos um dos Núcleos de Significação produzidos na pesquisa principal, com o objetivo de discutir a divisão sexual do trabalho na cozinha profissional. Este tem como proposta abordar aspectos relativos à divisão das atividades laborais na cozinha estudada e as posições ocupadas pelas trabalhadoras e pelos trabalhadores. Os indicadores que compuseram este Núcleo de Significação foram: a dificuldade feminina de inserção nos postos de trabalho, a cozinha quente como área masculina, a ausência de mulheres magarefes, posições naturalizadas, o trabalho na cozinha quente, o preparo da opção ovolácteavegetariana e o trabalho no setor de saladas. Destacamos também que as posições ocupadas pelas mulheres são de coadjuvantes no processo de produção, enquanto os homens assumem papéis proeminentes. Observamos também que o trabalho feminino é tido como complementar ao masculino. Assim, buscamos neste tópico, articular as falas apreendidas com as literaturas que abordam sobre temas referentes à divisão sexual do trabalho e às construções culturais em torno da alimentação.

Notamos na realização da pesquisa que a cozinha quente é um setor central no preparo dos alimentos, pois é o setor onde ocorre a cocção e preparação dos alimentos como arroz, feijão, guarnição e a carne, sendo estes os pratos principais. Conforme Felipe, que é ajudante, a cozinha quente é vista como "a área de produção":

O quente é a área de produção. Eu acho que essa parte é mais para homem devido ao peso, você pega muito peso. (Felipe grifo nosso) 
Podemos destacar dois aspectos em sua fala: primeiro que os demais setores, onde outros procedimentos são realizados, para ele não são considerados áreas de produção, e segundo que a cozinha quente (onde ocorre o pré-preparo de alguns alimentos e a cocção de todos) é mais adequada para homens que para mulheres. Tal discurso reflete o que observamos no estudo de Castro e Maffia (2012), no qual as autoras perceberam o direcionamento do trabalho masculino para a cozinha quente. Felipe caracteriza "o quente" como o centro da elaboração das refeições, como se todos os procedimentos de preparo estivessem centralizados em um único local. Desta forma, podemos perceber uma supervalorização da cozinha quente em detrimento dos demais setores da cozinha.

Observamos, ao analisar sua fala, que ele avalia as atividades desenvolvidas nesse setor como pesadas, e por conta dessa necessidade de força física o setor seria voltado para os homens. São atividades relacionadas ao preparo do prato principal que será servido no dia. Envolve cortes, condimentação, cocção, porcionamento da comida nas cubas, manipulação de grandes panelas, grelhas e chapas. Para Felipe, uma mulher só poderá trabalhar na cozinha quente se construir uma trajetória na empresa, pois ele acredita que não há a possibilidade de que uma trabalhadora seja selecionada para o setor no momento da contratação. Notamos isso quando ele relata:

Só que quando vai fazer entrevista eles não dão oportunidade [para as mulheres] eles nãodão. Para vocêter uma oportunidade dessa, para uma mulher dessa tá no quente ela já tem que tá na empresa e ela tem que tá mostrando o trabalho dela. Aí quem tá olhando ela, visando ela, vendo ela, dá uma oportunidade, mas pra entrar logo de cara não entra. Não é eu é a empresa (Felipe - grifo nosso).

Percebemos através do relato que existe uma discriminação de cunho sexual e de gênero que, segundo ele, ocorre no momento da contratação para trabalhar na cozinha quente. Os homens podem ser designados para esse setor no processo de contratação, enquanto as mulheres precisam construir uma carreira e "mostrar o trabalho delas" para então, de acordo com Felipe, fazerem jus ao labor na cozinha quente.

Observamos um discurso meritocrático no que diz respeito às oportunidades de inserção feminina no setor. Deste modo, seria necessário empenhar-se o suficiente para alcançar tal posto, pois de outro modo - "quando vai fazer entrevista" - não seria possível. Diante disso, ele ainda afirma:

Nessa área industrial a gente pega muito peso. Eles nunca vão colocar mulheres na frente, nunca. Você pode ter certeza. É a empresa que não aceita. (Felipe - grifo nosso) 
De acordo com Saffiotti (2013), a preferência da força de trabalho masculina nos postos de responsabilidade e de que depende o progresso da empresa, como é o caso da cozinha quente (que prepara o prato principal do dia), utiliza como justificativa para subalternidade das mulheres na hierarquia de posições a descontinuidade do trabalho feminino. Pôde-se verificar no caso estudado a falta de mulheres em posições hierárquicas mais altas, ou na "frente" do setor de cocção.

Sendo a cozinha quente, o local onde ocorre a cocção dos alimentos, os fatores biológicos como a maternidade e o ciclo menstrual são utilizados também no direcionamento dos cargos ocupados por homens e mulheres no local, como aponta Felipe:

É aquilo que eu lhe falei naquele dia mulher menstrua, engravida e tipo assim o patrão, ele olha tudo isso. Ele nunca, e tipo assim ele nunca vai ver uma mulher no quente, você pode ver, mas é quase que impossível. (Felipe - grifo nosso)

A gravidez e a menstruação também adquirem caráter simbólico no que diz respeito às representações em torno da alimentação. À exemplo disso, na obra Sexo e Temperamento, Margareth Mead (2000) relata em um dos seus estudos antropológicos que o povo Arabesh possuía diversos tabus alimentares, dentre eles afastar as mulheres menstruadas das aldeias e das atividades que são associadas ao alimento, pois considerava-se que elas têm o sangue impuro (Mead, 200o). Segundo Woortmann (2006), para diversas culturas o ciclo fisiológico da mulher é captado simbolicamente, se tornando critério demarcador de sua posição na sociedade. $\mathrm{O}$ autor ainda afirma que a menstruação é concebida como uma perigosa condição de desequilíbrio orgânico e estado de poluição. Percebemos, então, que na esfera alimentar, existem diversos aspectos referentes à relação entre gênero e alimento, por meio dos quais diferentes culturas partilham signos e significados expressados no cotidiano das relações sociais (Woortmann, 2006), como exemplifica a fala de Felipe.

A maternidade também foi pontuada pelo entrevistado como um impedimento da inserção da força de trabalho feminina em espaços de maior prestígio social (como é o caso da cozinha quente). Segundo Chies (2010), apesar das diferenças entre as classes sociais, a responsabilidade pela casa e pelos filhos é imposta às mulheres, pois quando donas de casa ou operárias, o cuidado com o lar fará parte do seu dia a dia. Acredita-se, por meio de um processo ideológico, que naturalmente o trabalho doméstico e o cuidado com a família pertencem estritamente às mãos femininas.

Nesse sentido, na busca do emprego as mulheres estão expostas a barreiras que impõem discursos que legitimam a ideia de que o seu labor não é produtivo. Sobre isso, Costa (2014) pontua que a possibilidade de engravidar em algum momento da vida inspira a imagem de que o trabalho feminino é inconstante, pois os possíveis afastamentos nos últimos meses que seguem o parto e nos primeiros após, impõem um caráter cíclico do labor feminino, reforçando os argumentos de exclusão da mulher 
no mercado de trabalho. A maternidade não pode ser encarada como uma carga unicamente das mulheres, visto que a sociedade estando interessada no nascimento e socialização das novas gerações, como uma condição de sua própria sobrevivência, ela deve pagar ao menos parte do preço da maternidade; neste caso, buscar soluções satisfatórias para os problemas de natureza profissional que a maternidade cria para as trabalhadoras (Saffiotti, 2013).

Na etapa de observações, notamos que a maioria das mulheres não se aproxima do fogão, elas mantêm uma distância do fogo e se aproximam de atividades associadas ao frio e à água (como preparar as saladas). Apesar do setor que Maria trabalha ser um lugar refrigerado, classificado como a cozinha fria, ela é uma das únicas trabalhadoras que em algum momento do seu trabalho lida com "o quente". Como responsável pela opção ovolácteavegetariana, ela acaba realizando todo o pré-preparo e metade do preparo na cozinha fria. No momento em que precisa cozinhar os alimentos, ela vai para a cozinha quente e, em poucos instantes, volta à cozinha fria. Quando se ausenta do trabalho nos dias úteis da semana, ela é substituída por Viviane. Sobre o procedimento realizado por elas na cocção da opção ovolácteavegetariana, ela relata:

Só [mexo com o fogão] quando eu tou na patissaria. Quando eu tou na patissaria eu tenho de ir para o fogo, fazer... botar molho para cozinhar, fazer o pirão. [...] na chapa quando eu tou na patissaria eu faço a panqueca ou a omelete, aí tem que ir pra chapa. (Viviane - grifo nosso)

O fogo sempre teve uma relevância no sistema alimentar. Foi através do ato de cozinhar os alimentos que o ser humano se distinguiu entre os demais animais. Associado à magia, ao sobrenatural e a ideia de vida, foi possivelmente uma das primeiras divindades (Franco, 2010). Desta maneira, é na cozinha quente que o cozimento dos alimentos é realizado, dando passagem à transformação do alimento cru em cozido que, segundo Lévis-Strauss (1965, apud Giordiani 2015), estaria relacionado ao momento no qual o homem transcendeu da natureza para a cultura (Giordiani, 2015).

Mesmo realizando algumas cocções na cozinha quente, Maria não é identificada como uma trabalhadora “do quente". Podemos concluir isso a partir da fala de Jorge:

O cozinheiro faz o prato principal, o ajudante faz o arroz e a guarnição e dona Maria faz a opção [ovolácteavegetariana]. (Jorge - grifo nosso)

Jorge se refere à Maria de forma distinta da maneira como fala dos outros profissionais, não a identificando em posição equivalente à dos ajudantes homens que trabalham na cozinha quente. Nesse sentido, ao relatar o que Maria faz, ele não deixa claro qual é sua profissão, como se ela não tivesse um lugar estabelecido na cozinha. 
Outra possibilidade de interpretação é que, por Maria desenvolver essa atividade de maneira mais frequente que outros ajudantes (diariamente, exceto alguns dias úteis e finais de semana), ele se refere a ela de maneira específica destacando seu nome. Nos dois casos, no entanto, notamos que o caráter pessoal toma destaque em relação ao caráter profissional, o que parece ser relevante quando consideramos os fatores de desigualdade até aqui encontrados entre os trabalhadores homens e mulheres. Sobre essa diferenciação, Chies (2010) afirma que independente de qual profissão homens e mulheres exerçam, se a subordinação da primeira pelo segundo é um ponto fixo na mentalidade de uma sociedade, estes não terão a mesma identidade profissional, mesmo que atuantes na mesma profissão. Assim, pontos em comum surgirão nessa relação, pois se fala da mesma profissão, porém existem diferenciais marcados pela questão de gênero.

Sendo Maria a profissional desta cozinha responsável pela opção ovolácteavegetariana, é importante ressaltar que ela, por ser ajudante de cozinha, teoricamente não deveria ser responsabilizada por essa atividade, visto que segundo a Classificação Brasileira de Ocupações (CBO) (Brasil, 2010) a função de uma ajudante de cozinha seria:

[...] auxiliam outros profissionais da área no pré-preparo, preparo e processamento de alimentos, na montagem de pratos. Verificam a qualidade dos gêneros alimentícios, minimizando riscos de contaminação. Trabalham em conformidade a normas de procedimento técnicos e de qualidade, segurança, higiene e saúde (Brasil, 2010).

A opção ovolácteavegetariana é consumida pelos comensais do restaurante como prato principal, em substituição a carne. Sobre sua responsabilidade ela relata:

Todos os tipos de refeição é... todas as opções [ovolácteasvegetarianas] quem faz sou eu, entendeu? Todas, todas as opções quem faz sou eu [...]Só o fim de semana, a turma do fim de semana faz, porque eu não trabalho fim de semana (Maria - grifo nosso).

Destacamos, neste ponto, a relação entre a carne (preparada pelo cozinheiro) e a opção ovolácteavegetariana (preparada pela ajudante). Se a carne é o prato principal e a opção ovolácteavegetariana é a substituição para aqueles que não consomem a carne, então a "opção" também deveria ser considerada como prato principal. No entanto, o que se nota é uma supervalorização da carne em detrimento da opção, o que leva à depreciação de quem a prepara, no caso Maria. Conforme Ribeira e Corção (2013), uma grande parcela da população mundial dá importância tão significativa à carne, a ponto de ser considerada fundamental na formação de suas refeições (Ribeiro \& Corção, 2013). 
Quando questionada sobre haver alguma atividade não adequada às mulheres na cozinha, Maria responde:

Dentro da cozinha? Sim. Por que... tem sim, por exemplo, uma mulher ela não pode ser açogueira, magarefe, né? [...] Eu acho porque, realmente o trabalho de magarefe, eu acho que é mais adequado para o homem, pela quantidade de carne, pela quantidade do esforço dos braços, eu acho que o homem tem mais essa vantagem. (Maria - grifo nosso)

Ela acredita que o trabalho de magarefe ${ }^{7}$ não é adequado para mulheres devido a força física necessária para trabalhar com a carne. Além disso, podemos notar na fala "eu acho que o homem tem mais essa vantagem" a multiplicidade de papéis que os homens podem desempenhar na cozinha, e as "vantagens" que ela acredita que eles possuem por biologicamente terem mais força física. Segundo Saffiotti (2013), a valorização da força física do homem serve como elemento de justificativa para a hierarquização dos sexos. Desta maneira, ressaltamos que com o desenvolvimento da tecnologia, a força física masculina não pode ser avaliada como um atributo essencial para o desempenho de certas atividades e direcionamento das pessoas para determinados cargos. Raimundo, que é magarefe, quando questionado se já viu mulheres exercendo a função de magarefe, afirma:

Como eu disse a você magarefe é muito puxado, o ritmo da mão, aquele ritmo mesmo que a gente tem na faca ali, aquela frieza ali, talvez mulher ali... não cai bem não viu? É muito puxado, se fosse uma área que fosse pequena, assim, poucas coisas para fazer, tá entendendo? Mas é muita alimentação para cortar, e acho que mulé não sei se aguenta não. [...] pra falar a sinceridade pra você, eu nunca vi, nunca vi. Nunca em nenhum lugar, nunca vi mulher magarefe (Raimundo - grifo nosso).

O cargo de magarefe, tanto para Maria quanto para Raimundo, está relacionado com a questão da força. Destarte, a quantidade de carne manuseada e o ritmo de trabalho, para ambos, justifica a inadequação da área para as mulheres trabalhadoras. A profissão de magarefe adquire, socialmente na cozinha, valoração, uma vez que é desempenhada por homens, tidos como mais fortes, e pela manipulação da carne.

A carne representa prestígio para diversos grupos sociais, sendo consumida como principal elemento da alimentação. Wedig et al (2008) afirmam em seu estudo, que para as famílias rurais a carne é considerada como "comida forte" e, neste sentido, estaria simbolicamente associada ao pai, que seria o elemento mais forte da família e este a prepararia nas ocasiões comemorativas (Wedig et al, 2008). Desta forma, para

7 Profissional responsável pela manipulação de carnes, indo dos cortes a condimentação. 
as autoras, a carne seria também um alimento mais valorizado. Outro exemplo é a cozinha guarani, estudada por Giordiani (2015), onde o churrasco seria preparado pelos homens da aldeia e as mulheres estariam excluídas do processo. Destacamos que no meio urbano esse tipo de situação referente ao preparo do churrasco também adquire uma imagem masculina (Giordiani, 2015).

Desta maneira, podemos observar que há uma correlação entre o trabalho do magarefe, o lidar com a carne e o indivíduo masculino. Esses elementos adquirem atributos valorativos que excluem o feminino de determinadas práticas. Assim, destacamos que os aspectos simbólicos permeiam neste cenário em paralelo aos aspectos físicos.

Na etapa de observação, percebemos ainda que nenhuma das trabalhadoras executou alguma tarefa que fosse relacionada ao preparo da carne. As atividades relacionadas à manipulação destas eram realizadas pelos homens da cozinha estudada e às mulheres restava o serviço que envolvia o trabalho com os vegetais.

É no setor das saladas onde ocorre o pré-preparo e preparo destas, lá trabalham apenas as copeiras e que realizam desde a lavagem até a montagem nas cubas. As saladas são tidas como acompanhamento das refeições servidas no RI. Segundo Ribeiro e Corção (2013), no fim da estrutura de hierarquização dos alimentos, estariam os vegetais, que seriam considerados insuficientes para refeição, representando assim o papel de complemento ou de guarnição. Deste modo, o trabalho realizado pelas copeiras pode ser considerado como complementar ao dos cozinheiros e ajudantes (Ribeiro \& Corção, 2013).

De acordo com Hirata e Kergoat (2007) a ideia de complementaridade entre os sexos faz parte da tradição funcionalista da complementaridade de papéis, ou seja, cada gênero tem sua função. Desta maneira, são criados papéis a serem interpretados e dá-se a concepção de vínculo social entre eles. Segundo as autoras, um reflexo disso é o trabalho profissional que gera a divisão de diversas modalidades de empregos, possibilitando a reprodução desses papéis (Hirata \& Kergoat, 2007).

Notamos também que as copeiras, além de produzirem as saladas, desempenham diversas atividades no restaurante, dentre elas servir as refeições para os estudantes, catar o feijão e lavar as frutas para sobremesa. Como vimos, o grande contingente de trabalhadores que exercem essa função na cozinha estudada são mulheres. Os copeiros que existem no restaurante são contratados apenas para atividades como confeccionar os sucos e fazer a reposição da comida nas rampas, sendo estas ligadas à questão do peso.

Observamos que o preparo das saladas é caracterizado por uma dinâmica repetitiva e monótona, por diversas vezes as trabalhadoras manipulam equipamentos mais baixos que elas, lavam e cortam legumes e hortaliças o dia todo. Cátia, que é copeira e trabalha com a confecção das saladas, relata:

Faço salada a hora que eu chego até a hora de ir embora. Lavo folha o tempo todo. Higienizo tudo direitinho, já peguei tanto a prática que num instante eu lavo. [...] um pouco cansativo, mas 
é uma coisa que eu gosto de fazer. [...] É um serviço cansativo entendeu? Eu gosto de fazer esse serviço, agora que é repetitivo é, mas ai dentro não tem outra área. (Cátia - grifo nosso)

Segundo Cátia, mesmo com as condições de trabalho que possui, ela diz gostar do serviço, visto que na cozinha do restaurante ela não vê outra oportunidade de trabalho para si. Oliveira (1999) afirma que as mulheres estão em diferentes profissões que particularmente requisitam de destreza manual, estes são considerados os guetos femininos de trabalho. A autora ainda afirma que a repetitividade, a monotonia, a falta de criatividade das tarefas, a submissão a ritmos acelerados de trabalho, o número reduzido de funcionários e o trabalho hierarquizado são fatores que ocasionam problemas de saúde às trabalhadoras e que podem provocar a Lesão por Esforço Repetitivo (LER). (Oliveira, 1999)

Conforme Costa (2014), a força de trabalho feminina é utilizada de acordo com as necessidades do mercado, à medida que se tem ausência de força de trabalho masculina. Assim, podemos pressupor que a probabilidade de Cátia sair dessas atividades e ir para outros setores, como a cozinha quente ou o açougue, é menor, pois como vimos, os homens possuem prioridade nesses setores.

Observamos abaixo na fala de Jorge, que é cozinheiro, uma legitimação dos lugares ocupados por trabalhadoras e trabalhadores no que tange a cozinha estudada. Quando questionado sobre os trabalhos que as mulheres e os homens podem desempenhar, ele responde:

Acho, tem vários. Aqui na cozinha o que é adequado para a mulher é a salada, frutas, fica ali na rampa servindo, isso é adequado para mulher. Agora para pôr na rampa, cozinhar, eu acho mais adequado para homem no meu ponto de vista. (Jorge - grifo nosso)

Porém, isto está longe de ser uma realidade apenas do RI estudado. O cozinheiro relata já ter vivenciado isso em outros estabelecimentos que trabalhou:

[...] isso é comum mesmo. Em todos os lugares que eu já trabalhei, a maioria das mulheres trabalham na salada e os homens na área quente, todas as áreas [...] É, as mulheres ficam mais nas saladas, quando fica na cozinha só escolhe só a opção [ovolácteavegetariana], só coisa leve mesmo, quem faz coisa pesada mesmo é só os homens. (Jorge - grifo nosso)

Observamos que a divisão das atividades entre homens e mulheres nas cozinhas industriais obedece aos critérios sociais que impõem papéis femininos e masculinos. Para ele, isto é comum, o processo de produção acaba naturalizando e definindo as posições ocupadas entre os trabalhadores, assim relaciona o trabalho 
leve ao feminino e o pesado ao masculino. Observamos que os critérios apresentados por Jorge tem como base a divisão sexual do trabalho. Hirata \& Kergoat (2007) afirmam que esta é uma forma de divisão social do trabalho que tem como dois princípios organizadores: o princípio de separação (existem trabalhos de homens e de mulheres) e o hierárquico (um trabalho de homem vale mais que um trabalho de mulher). Tais princípios, segundo as autoras, são válidos para todas as sociedades conhecidas, no tempo e no espaço. Estes podem ser aplicados através de um processo de legitimação, a da ideologia naturalista que rebaixa o gênero ao sexo biológico, balizando as práticas sociais a meros "papéis sociais" sexuados que remetem ao destino natural da espécie (Hirata \& Kergoat, 2007).

\section{Conclusão}

Este texto teve como objetivo discutir a divisão sexual do trabalho em uma cozinha profissional. Deste modo, observamos que a divisão das atividades laborais na cozinha estudada utiliza como um dos seus critérios, o gênero; relacionando assim o que seriam espaços e tarefas femininas e masculinas. Tais critérios direcionam as atividades que necessitam de maior desempenho físico aos homens e as tomam como as mais importantes e fundamentais do processo de produção. Os exemplos observados foram o labor no setor "cozinha quente", espaço destinado a preparação dos pratos principais, e o trabalho do magarefe, labor relacionado a manipulação de carnes. Tal lógica parte da hierarquização de posições e vincula o labor e a identidade masculina à elementos que representam no campo simbólico e cultural, aspectos de poder e relevância social.

Notamos que as mulheres enquanto ligadas a tarefas como preparo de saladas, opção ovolácteavegetariana, o serviço da alimentação, entre outras atividades, são socialmente desconsideradas e depreciadas por estarem atreladas as funções tidas como complementares ao processo de produção da comida do RI. Nesse sentido, destacamos que a relevância dada ao tipo de trabalho irá direcionar quem serão as pessoas que o farão. Quando alocadas nos mesmos cargos (como o caso de dona Maria), as tarefas exercidas não apresentam os mesmos aspectos valorativos. Os aspectos comumente associados às mulheres no mundo do trabalho, tais como menstruação, gravidez e fragilidade, são utilizados como determinantes no direcionamento do trabalho feminino às funções opostas às masculinas e consequentemente de menor valor social na cozinha profissional. Diante de tais justificativas, na cozinha do RI, as mulheres ficam limitadas às posições subordinadas, sem almejar mudanças estruturais e possíveis melhorias nas condições de trabalho.

É importante destacar que as tarefas realizadas pelas trabalhadoras também requerem desgaste físico, ficando estas, expostas às atividades mais precárias, repetitivas e monótonas, possibilitando o desenvolvimento de problemas de saúde. 
Por fim, o referencial teórico metodológico utilizado nos possibilitou compreender como os significados dados ao trabalho de mulheres e homens na cozinha estudada estão pautados no modo pelo qual as relações de gênero são produzidas historicamente, socialmente e culturalmente na humanidade. Portanto, os sentidos atribuídos pelas pessoas entrevistadas não estão desconectados de uma realidade que se dá na materialidade. Acreditamos que tal estudo possa contribuir para desnaturalizar discursos e posições relacionadas à cozinha profissional e colaborar para a ruptura de arranjos que geram desigualdades e contextos subalternos para com o trabalho culinário feminino.

\section{Referências}

AGUIAR, Wanda Maria J.; OZELLA, Sergio. (2013). Apreensão dos sentidos: aprimorando a proposta dos núcleos de significação. Ver. Bras. de Est. Ped., Brasília, v. 94, n. 236, p. 299-322, jan./abr. Disponível em: http://www.scielo.br/pdf/rbeped/ v94n236/15.pdf

(200o). Reflexões a partir da Psicologia Sócio-Histórica sobre a categoria

“consciência”. Cadernos de Pesquisa, n. 110, p. 125-142, jul/dez. Disponível em: http:// www.scielo.br/pdf/\%oD/cp/n110/n110ao5.pdf

BARBOSA, Lívia (2012). Os donos e as donas da cozinha. In: FREITAS, Maria Ester de; DANTAS, Marcelo. Diversidade Sexual e Trabalho. São Paulo: Editora Cengage Learning.

BRASIL (2016). Ministério do trabalho e emprego. Classificação Brasileira de Ocupações. Brasília. Disponível em: http://www.mtecbo.gov.br/cbosite/pages/home. jsf.

CHIES, Paula (2010). Identidade de gênero e identidade profissional no campo do trabalho. Florianópolis, Estudos Feministas, v. 18, n. 02, p. 507-528, maio/agosto. Disponível em: http://www.scielo.br/pdf/ref/v18n2/13.pdf

COLLAÇO, Janine Helfst Leicht. (2008). Cozinha Doméstica e Cozinha Profissional: Do Discurso Âs Práticas. Cad. Esp. Fem., v. 19, n. o1, p. 143-171. Jan./Jul. Disponível em: www.seer.ufu.br/index.php/neguem/article/.../1728

COSTA, Ana Alice. (2014). A mulher na força de trabalho. Revista Feminismos, v.2, n.2, p. 14-24. Mai./Ago. Disponível em: http://www.feminismos.neim.ufba.br/index.php/ revista/article/viewFile/143/110 
DÓRIA, Carlos Alberto. (2014). O estilo feminino de cozinhar. In: DÓRIA, Carlos

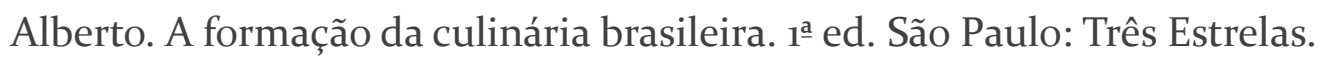

GONÇALVES, Maria da Graça Marchina (2002). A psicologia como ciência do sujeito e da subjetividade a historicidade como noção básica. In: BOCK, Ana. GONÇALVES, Maria. FURTADO, Odair. Psicologia Sócio-histórica: uma perspectiva crítica da psicologia. Editora Cortez: São Paulo.

GIORDANI, Rubia Carla Formighieri. (2015) Mulheres e água, homens e fogo. Gênero e transformação na cozinha guarani. Sociedade e Cultura, v.18, n.1, p.9110o. jan. /jun. Disponível em: https://revistas.ufg.emnuvens.com.br/fchf/article/ viewFile/406o6/20724

KERGOAT, Danièle; HIRATA, Helena. (2007). Novas Configurações da Divisão Sexual do Trabalho. Cadernos de Pesquisa. São Paulo, n.132, p. 595-6o9. set-dezembro. Disponível: http://www.scielo.br/pdf/cp/v37n132/ao537132.pdf.

MEAD. Margareth. (200o). Sexo e temperamento. 4 Edição. São Paulo: Perspectiva.

OLIVEIRA, Eleonora Menicucci de. (1999) A mulher, a sexualidade e o trabalho. $\mathbf{1}^{\underline{a}}$ Edição. São Paulo: Editora Hucitec.

PASSOS, Elizete Silva (1997). Presença feminina nos cursos de graduação da UFBA. In: COSTA, Ana Alice; ALVES, Ivia Iracema (org.). Ritos, Mitos e Fatos: Mulher e gênero na Bahia. Salvador: Editora FFCH/UFBA, p.135-15o.

RIBEIRO, Cilene da S. G.; CORÇÃO, Mariana. (2013) O consumo de carne no Brasil: entrevalores socioculturais e nutricionais. Demetra, v.8, n.3, p. 425-438. Disponível em: http://www.e-publicacoes.uerj.br/index.php/demetra/issue/view/535\#.VynwfoQrLI

SAFFIOTTI, Heleieth. (2013). A mulher na sociedade de classes: mito e realidade. São Paulo: Expressão Popular.

SCOTT, Joan. (1990). Gênero: uma categoria útil de análise histórica. In: Educação e Realidade, v. 16, n. 2, p. 5-22. Disponível em: http://www.seer.ufrgs.br/index.php/ educacaoerealidade/article/view/71721/40667

WEDIG, Josiane Carine; MARTINS, Viviane Santi; MENASCHE, Renata. (20o8) Plantar, criar, comer: classificações da comida e das pessoas no interior de famílias rurais. In: Fazendo Gênero 8 - Corpo, Violência e Poder, Florianópolis. Anais. Florianópolis. Disponível em: http://www.fazendogenero.ufsc.br/8/sts/ST6/WedigMartins-Menasche_o6.pdf. Acesso em: o4 de abril de 2016. 
WOORTMANN, Klass. (2006). O sentido simbólico das práticas alimentares. In: ARAÚJO, W. M.C.; TENSER, C.M.R. (Org.). Gastronomia: cortes e recortes. Brasília: Senac, p. 23-55.

Recebido: 25.12.2017

Aceito: 01.09.2018 